\title{
Computer Simulation of the Performance of Industrial Gas Turbines with Application to Mosul Power Station
}

\author{
Dr. Ghalib. Y. Kahwaji Dr. A. R. Habbo Mohammed \\ Department of Mechanical Engineering, College of Engineering, \\ Mosul University, Mosul, Iraq
}

\begin{abstract}
:-
A thermodynamic simulation of the power generation gas turbine of the Mosul gas turbine power station was carried out, and its performance was observed. The simulation included detailed modeling of the compressor, the combustion chamber and the turbine based on the physics as well as the common practice in the field. Comparison of the simulation code results with the field collected data indicated agreement to within $2 \%$ of the compared parameters. The developed code then used to study the effect of varying the ambient temperature on the performance of the system. The results showed a decrease of up to $21 \%$ in the power output when the ambient temperature increases from its ISO value of $15{ }^{\circ} \mathrm{C}$ to $45{ }^{\circ} \mathrm{C}$. Comparison between running the system under constant turbine inlet temperature and constant turbine power output were also conducted.
\end{abstract}

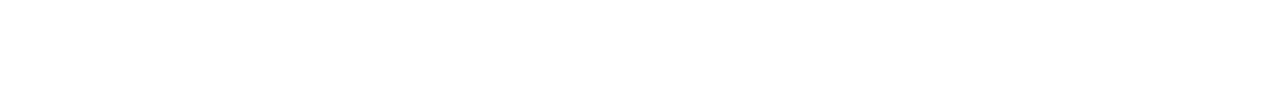

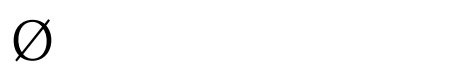

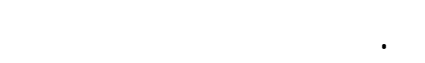

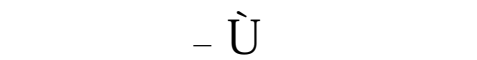

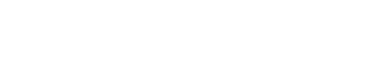

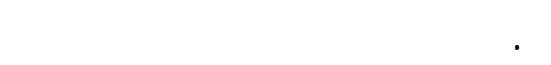

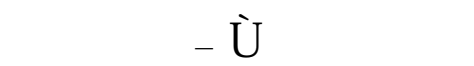

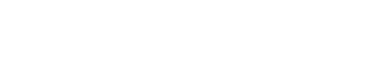

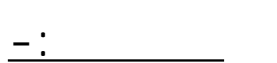

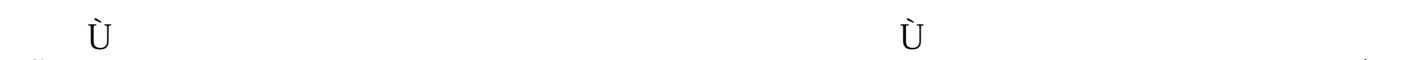

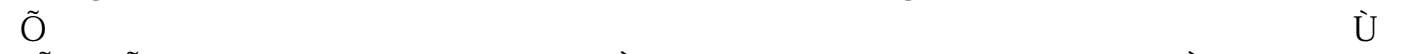

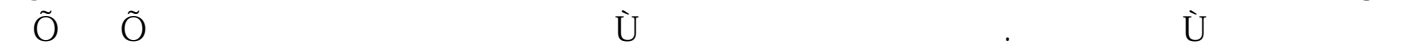

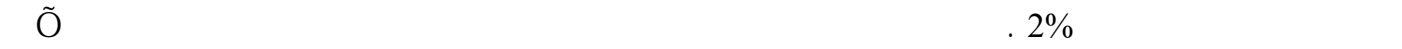

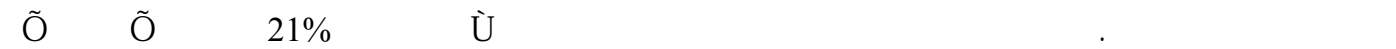

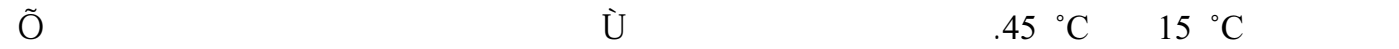

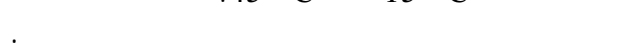

\section{Submitted 10 ${ }^{\text {th }}$ May $2004 \quad$ Accepted $6{ }^{\text {th }}$ April 2005}




\section{$\underline{\text { Nomenclature }}$}

$\begin{array}{llll}\mathrm{A} & \text { Annulus area }\left(\mathrm{m}^{2}\right) & \mathrm{R}^{\circ} & \text { Air gas constant }(\mathrm{kJ} / \mathrm{kg} . \mathrm{K}) \\ \mathrm{C} & \text { Absolute velocity }(\mathrm{m} / \mathrm{sec}) & \mathrm{R}_{\mathrm{s}} & \text { Stage pressure ratio } \\ \mathrm{C}_{\mathrm{a}} & \text { Axial velocity }(\mathrm{m} / \mathrm{sec}) & \mathrm{r} & \text { Annulus radius }(\mathrm{m}) \\ \mathrm{C}_{\mathrm{Da}} & \text { Annulus drag coefficient } & \mathrm{T} & \text { Temperature }(\mathrm{K}) \\ \mathrm{C}_{\mathrm{Dp}} & \text { Profile loss coefficient } & \mathrm{TIT} & \text { Turbine inlet temperature }(\mathrm{K}) \\ \mathrm{C}_{\mathrm{Ds}} & \text { Secondary loss coefficient } & \Delta \mathrm{T}_{\mathrm{s}} & \text { Stage temperature rise }(\mathrm{K}) \\ \mathrm{C}_{\mathrm{L}} & \text { Lift coefficient } & \mathrm{U} & \text { Mean blade speed }(\mathrm{m} / \mathrm{sec}) \\ \mathrm{C}_{\mathrm{p}} & \text { Specific heat }(\mathrm{kJ} / \mathrm{kg} . \mathrm{K}) & \mathrm{W}_{\mathrm{s}} & \text { Stage work }(\mathrm{kJ} / \mathrm{kg}) \\ \mathrm{C} & \text { Chord } & \mathrm{V} & \text { Relative velocity }(\mathrm{m} / \mathrm{sec}) \\ \mathrm{Ma} & \text { Mach number } & \alpha & \text { Air inlet angle }(\text { degree }) \\ \mathrm{N} & \text { Rotational speed (rpm) } & \beta_{*} & \text { Air outlet angle }(\text { degree }) \\ \mathrm{n}_{\mathrm{b}} & \text { Number of blades } & \varepsilon & \text { Air deflection angle (degree) } \\ \mathrm{P} & \text { Pressure (bar) } & \Lambda & \text { Degree of reaction } \\ \Delta \mathrm{P} & \text { Pressure differences (bar) } & \rho & \text { Density }\left(\mathrm{kg} / \mathrm{m}^{3}\right) \\ \mathrm{R}_{\mathrm{ov}} & \text { Overall pressure ratio } & \gamma & \text { Specific heat ratio } \\ & & & \end{array}$

$\begin{array}{ll}\mathrm{a} & \text { Axial } \\ \mathrm{b} & \text { Blade } \\ \mathrm{comb} & \text { Combustion } \\ \mathrm{R} & \text { Rotor } \\ \mathrm{r} & \text { Root } \\ \mathrm{m} & \text { Mean } \\ \mathrm{N} & \text { Nozzle } \\ \mathrm{t} & \text { Tip } \\ \mathrm{s} & \text { Stage } \\ \mathrm{w} & \text { Whirl } \\ 1,2, . . \text { etc } & \text { State number }\end{array}$

\section{1-Introduction}

A gas turbine in its most common form is a heat engine consisting of three components, a compressor, a combustion chamber and a turbine. A schematic diagram for a simple gas turbine is shown in figure (1). Air is drawn in by the compressor and delivered to the combustion chamber at a pressure of $(8-12)$ bar depending on the design. Liquid or gaseous fuel is commonly used to increase the temperature of compressed air through a combustion process. Hot gases leaving the combustion chamber expands in the turbine which produce work and finally discharges to the atmosphere $[1,2,3]$. Gas turbines installed until the mid seventies suffered from low efficiency and poor reliability. This limited their use to peak power demand and as stand-by power units [4]. 


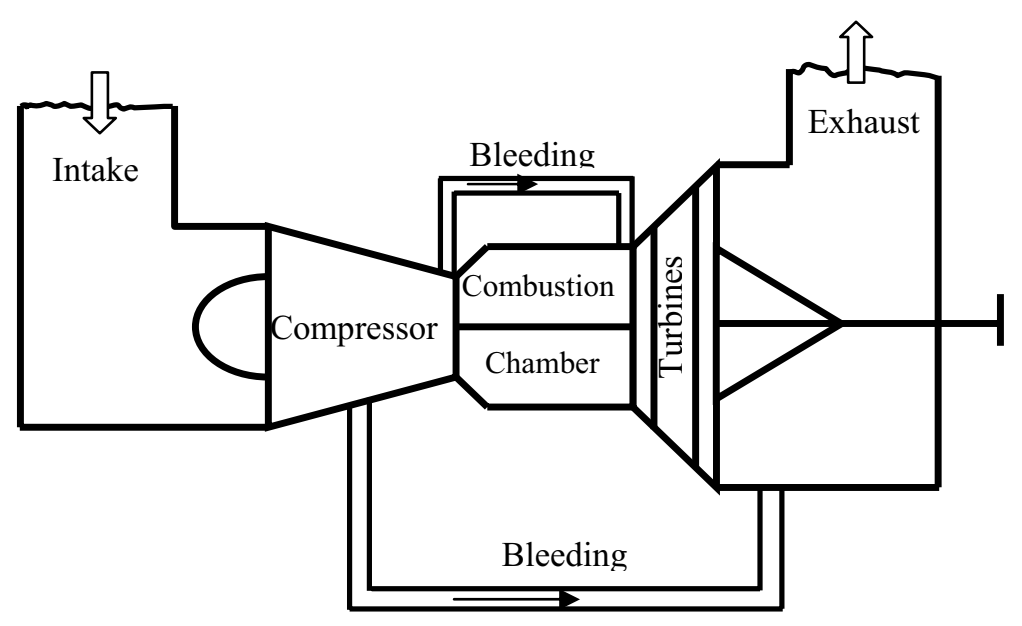

Figure (1): Pure Industrial Gas Turbine Schematic

However, recent developments in aerodynamics have led to significant increase in compressor and turbine efficiencies (up to 90\%), as well as the adventure in material science to come-up with special alloys that can withstand high temperatures enabled the gas turbine to enter the competition as a main power plant for generating electricity [5]. Recent rapid growth in electricity demand experienced in Iraq resulted in the need to build power plants that generate maximum output at summer ambient temperature to meet such demand. Due to their installation time and low installation cost, gas turbines are often used to meet this peak demand. However, one disadvantage that penalizes the gas turbine power rating is the inverse effect of the ambient temperature on the turbine power output $[1,2,3]$. Therefore, the aim of this study is to estimate the reduction in power generation of Mosul gas turbine unit during summer seasons due to the increase in inlet air temperature in an attempt to investigate various methods of treating such a problem.

\section{2- Mathematical Model}

The present study deals with single shaft gas turbines similar to that one installed at the Mosul gas turbine power station. As shown in figure (2), single shaft gas turbines are configured in one continuous shaft and, therefore, all stages operate at the same speed. These types of units are typically used for generator drive application, where significant speed variation is not required.

The simulation procedure involves the casting of mathematical models of each components making up the gas turbine system and in particular the axial flow compressor and turbine. The overall system performance may then be evaluated by combining these models under the normal sequence of operation of the whole system. The following assumptions were considered: -

1 -The working fluid is air and treated as perfect gas.

2-The specific heats of air and combustion products are temperature dependent.

3-The compression and expansion process are adiabatic and irreversible. 
4- There is no pressure loss in the inlet and exhaust ducting.

5- The rotational speed is assumed to be constant.

6- The mass flow rate through the compressor and turbine are equal.

7-The amount of heat loss from the combustion chamber is small, and can be ignored

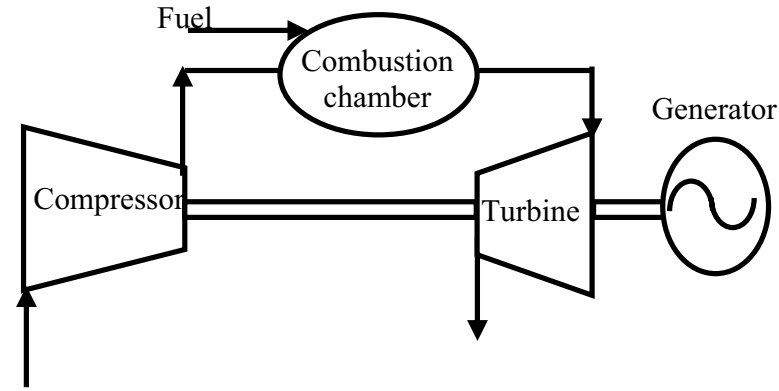

Figure (2): Simple single shaft gas turbine

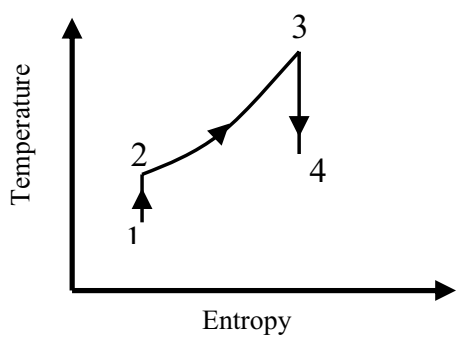

T-S diagram

2.1 Axial Flow compressor: An axial flow compressor stage consists of a rotor followed by a stator, the rotor carrying the moving blades and the stator is stationary row of blades. The basic principle of axial flow compressor is the acceleration of working fluid, followed by diffusion to convert acquired kinetic energy into a pressure rise. This process occurs in a number of stages and can be evaluated by considering the passage of the fluid through one stage [6,7]. Consider two-dimensional flow, means that the flow velocity will have two components, an axial component $\left(\mathrm{C}_{\mathrm{a}}\right)$ and a whirl component $\left(\mathrm{C}_{\mathrm{w}}\right)$. It is first assumed that the air approaches the rotor blades with absolute velocity $\mathrm{C}_{1}$ at an angle $\alpha_{1}$ to the axial direction as shown in figure (3).

The absolute velocity $C_{1}$ combine with mean blade speed $U$ to give the relative velocity at an angle $\beta_{1}$ as shown in the upper triangle. However, after air passing through the diverging passage formed between rotor blades which do work on the air and increase its absolute velocity, the air emerge with relative velocity $V_{2}$ at an angle $\beta_{2}$ which is less than $\beta_{1}$. Since $V_{2}$ is less than $V_{1}$ due to
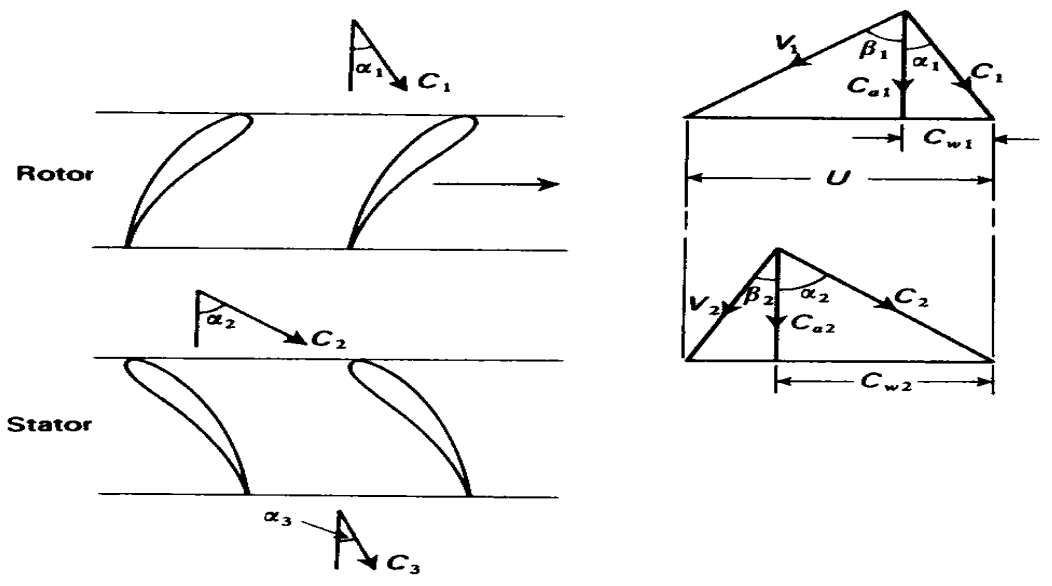

Figure (3): Velocity triangle for one stage 
divergence of the passage, some pressure rise will be accomplished in the rotor. The velocity $V_{2}$ in combination with $U$ gives the absolute velocity $C_{2}$ at the exit from the rotor at an angle $\alpha_{2}$ as shown in lower velocity triangle.

The air then passes through the passages formed by the stator blades where in it is further diffused to velocity $C_{3}$ at an angle $\alpha_{3}$, which in most designs is arranged to equal $\alpha_{1}$ so that it is prepared for entry to the next stage.

From the geometry of the velocity triangle, two basic equations are formed:

$\mathrm{U}=\mathrm{C}_{\mathrm{a}}\left(\tan \alpha_{1}+\tan \beta_{1}\right)=\mathrm{C}_{\mathrm{a}}\left(\tan \alpha_{2}+\tan \beta_{2}\right)$

the work done per unit mass due to change of angular momentum of air is given as:

$$
\mathrm{W}=\mathrm{U}\left(\mathrm{C}_{\mathrm{w} 2}-\mathrm{C}_{\mathrm{w} 1}\right)
$$

and can be written in terms of the axial velocity as:

$\mathrm{W}=\mathrm{U} \mathrm{C}_{\mathrm{a}}\left(\tan \alpha_{2}-\tan \alpha_{1}\right)=\mathrm{U} \mathrm{C}_{\mathrm{a}}\left(\tan \beta_{1}-\tan \beta_{2}\right)$ in terms of the stage temperature difference, it is given by:

$$
\mathrm{W}=\mathrm{c}_{\mathrm{p}}\left(\mathrm{T}_{2}-\mathrm{T}_{1}\right)=\mathrm{c}_{\mathrm{p}} \Delta \mathrm{T}_{\mathrm{os}}
$$

and for repeatable stages $\Delta \mathrm{T}_{\mathrm{os}}=$ constant $=\Delta \mathrm{T}_{\mathrm{s}}$, hence from equations 3 and 4

$$
\begin{gathered}
\Delta \mathrm{T}_{\mathrm{s}}=\frac{\mathrm{UC}_{\mathrm{a}}}{\mathrm{c}_{\mathrm{p}}}\left(\tan \beta_{1}-\tan \beta_{2}\right) \\
\mathrm{R}_{\mathrm{s}}=\left[1+\frac{\eta_{\mathrm{s}} \Delta \mathrm{T}_{\mathrm{s}}}{\mathrm{T}_{\mathrm{o} 1}}\right]^{\frac{\gamma-1}{\gamma}}
\end{gathered}
$$

and the pressure ratio for one stage is given as:

where $T_{o 1}$ and $\eta_{s}$ are the inlet stagnation temperature and the stage efficiency. At this point another parameter, "the degree of reaction $(\Lambda)$ ", is introduced. It is defined as the ratio of rotor static enthalpy rise to the stage static enthalpy rise. Since the choice of degree of reaction plays an important role in axial compressor design, it is useful to find a formula for it in terms of various velocities and air angles associated with the stage. Assuming that $\mathrm{C}_{1}=\mathrm{C}_{3}$, and $\Delta \mathrm{T}_{\mathrm{s}}=\Delta \mathrm{T}_{\mathrm{os}}$, the degree of reaction is equal to:

$$
\Lambda=\frac{\Delta \mathrm{T}_{1}}{\Delta \mathrm{T}_{1}+\Delta \mathrm{T}_{2}}
$$

where $\Delta T_{1}$ and $\Delta T_{2}$ are the temperature rise in the rotor and stator respectively. From equations 4 and 5, the degree of reaction can be put in the form of

$$
\Lambda=\frac{\mathrm{C}_{\mathrm{a}}}{2 \mathrm{U}}\left(\tan \beta_{1}+\tan \beta_{2}\right)
$$

Practically, it is desirable to have the degree of reaction in the vicinity of 0.5 to allow the rotor and stator to equally share the work burden. This yields, from equations 1 and 2 , that $\alpha_{1}=\beta_{2}$ and $\beta_{1}=\alpha_{2}$ under the condition that $C_{a}=$ constant.

Furthermore, assuming a constant axial velocity throughout the compressor length, and taking into consideration the allowable size, weight and the rotational speed of the compressor, the stage temperature rise is chosen to be in the range of $10-25{ }^{\circ} \mathrm{C}$ for subsonic compressor $[6,7]$. The air angles at the design diameter, the mean diameter, are usually the most convenient $\left(\alpha_{1}, \beta_{1}, \alpha_{2}\right.$ and $\beta_{2}$ ) to be found, this can be achieved by putting the degree of reaction equal to 
$50 \%$ since the axial velocity $\mathrm{C}_{\mathrm{a}}$ and $\Delta \mathrm{T}_{\mathrm{s}}$ are known. After finding the values of $\alpha_{1}, \beta_{1}, \alpha_{2}$, and $\beta_{2}$, the next step will be the caculation of the diameter of the annulus. The mean radius $\left(r_{m}\right)$ related to the mean blade speed and rotational speed as:

$$
\mathrm{r}_{\mathrm{m}}=\frac{\mathrm{U}}{2 \Pi \mathrm{N}}
$$

The annulus area, $A=2 \pi r_{m} h$, must satisfy the continuity equation $\mathrm{m}=\rho \mathrm{C}_{\mathrm{a}} \mathrm{A}$

where $\quad \mathrm{m}=$ mass flow rate of air $(\mathrm{kg} / \mathrm{sec})$

$$
\begin{array}{r}
A=\text { annulus area }\left(\mathrm{m}^{2}\right) \\
\rho=\text { density }\left(\mathrm{kg} / \mathrm{m}^{3}\right)
\end{array}
$$

The inlet air density is a function of the inlet conditions and given by:

$$
\begin{gathered}
\rho_{1}=\frac{\mathrm{P}_{1}}{\mathrm{R}^{\circ} \mathrm{T}_{1}} \\
\mathrm{~T}_{1}=\mathrm{T}_{\mathrm{o} 1}-\frac{\mathrm{C}_{1}^{2}}{2 \mathrm{c}_{\mathrm{p}}} \\
\mathrm{P}_{1}=\frac{\mathrm{P}_{\mathrm{o} 1}}{\left(\mathrm{~T}_{\mathrm{o} 1} / \mathrm{T}_{1}\right)^{\frac{\gamma}{\gamma-1}}} \\
\mathrm{~h}=\frac{\mathrm{m}}{2 \Pi \mathrm{r}_{\mathrm{m}} \rho_{1} \mathrm{C}_{\mathrm{a}}}
\end{gathered}
$$

where $T_{1}$ and $P_{1}$ is calculated as:

Figure (4) presents the air deflection angle $\left(\varepsilon^{*}=\beta_{1}-\beta_{2}\right)$ is plotted against air inlet angle with pitch to chord ratio $(\mathrm{s} / \mathrm{c})$ as parameter. This set of master curves, is of a great value to the designer because, having fixed any two variables involved, an appropriate value for the third may be determined. In this study, the inlet and outlet angles have been fixed, thus the suitable pitch/chord ratio can be obtained.

The number of blades in each row plays an important role in finding the blade chord length. In order to assess this number, the aspect ratio $(\mathrm{h} / \mathrm{c})$ of the

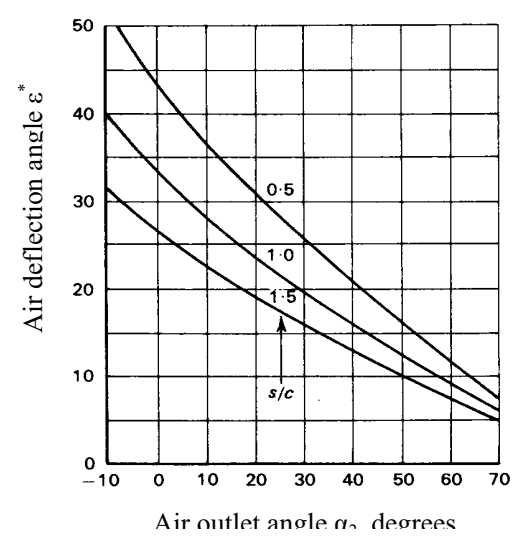

Figure (4): Design deflection 
blade should be assumed due to its effect on the secondary losses. Assuming aspect ratio $(\mathrm{h} / \mathrm{c})=3.0$, thus the value of chord length $\mathrm{c}$ can be obtained since the height of the blade has been calculated, i.e. $\mathrm{c}=\mathrm{h} / 3$. Furthermore, the pitch/chord ratio is obtained from figure (4), according to the value of the air outlet angle $\left(\alpha_{2}\right)$ and the air deflection angle $\left(\varepsilon^{*}=\beta_{1}-\beta_{2}\right)$. Therefore, the pitch length can be worked out as:

$$
\mathrm{s}=\left(\frac{\mathrm{s}}{\mathrm{c}}\right) *\left(\frac{\mathrm{h}}{3}\right)
$$

and number of blades would be evaluated using the following formula:

$$
\mathrm{n}_{\mathrm{b}}=\operatorname{int}\left(\frac{2 \pi \mathrm{r}_{\mathrm{m}}}{\mathrm{s}}\right)
$$

The stage performance of any axial compressor should be examined with regard to its efficiency. The stage efficiency is dependent on the total drag coefficient $\left(\mathrm{C}_{\mathrm{D}}\right)$ for each of the blades comprising the stage. The total drag coefficient is given by:

$$
\mathrm{C}_{\mathrm{D}}=\mathrm{C}_{\mathrm{Dp}}+\mathrm{C}_{\mathrm{Da}}+\mathrm{C}_{\mathrm{Ds}}
$$

where $\mathrm{C}_{\mathrm{Dp}}, \mathrm{C}_{\mathrm{Da}}$ and $\mathrm{C}_{\mathrm{Ds}}$ are the profile drag coefficient, the annulus drag coefficient and the secondary loss coefficient, respectively. The values of these coefficients can be determined using the following formula[6]:

$$
\begin{aligned}
\mathrm{C}_{\mathrm{Dp}} & =\left(\frac{\mathrm{s}}{\mathrm{c}}\right)\left(\frac{\overline{\mathrm{w}}}{\frac{1}{2} \rho \mathrm{V}_{1}^{2}}\right)\left(\frac{\cos ^{3} \alpha_{\mathrm{m}}}{\cos ^{2} \alpha_{1}}\right) \\
\mathrm{C}_{\mathrm{Ds}} & =0.018 \mathrm{C}_{\mathrm{L}}^{2} \\
\mathrm{C}_{\mathrm{Da}} & =0.02\left(\frac{\mathrm{s}}{\mathrm{h}}\right)
\end{aligned}
$$

Then using values of $\left\{\overline{\mathrm{w}} / \frac{1}{2} \rho \mathrm{V}_{1}^{2}\right\}$ which can be obtained from the curves of figure (5), and the calculated value of $(\mathrm{s} / \mathrm{c})$ for the blade, $\mathrm{C}_{\mathrm{Dp}}$ can be calculated from equation 18. Finally, the overall drag coefficient $\left(\mathrm{C}_{\mathrm{D}}\right)$ can be assessed using equation 17. Furthermore, the theoretical pressure rise through the blade row is found using the following formula:

$$
\Delta \mathrm{P}_{\mathrm{th}}=\frac{1}{2} \rho \mathrm{C}_{\mathrm{a}}^{2}\left(\tan ^{2} \alpha_{1}-\tan ^{2} \alpha_{2}\right)
$$

At this point, the blade efficiency, $\eta_{b}$, which is defined as the ratio of the actual pressure rise to theoretical pressure rise, can be found as:

$$
\eta_{\mathrm{b}}=1-\frac{\overline{\mathrm{w}} / \frac{1}{2} \rho \mathrm{V}_{1}^{2}}{\Delta \mathrm{p}_{\text {th }} / \frac{1}{2} \rho \mathrm{V}_{1}^{2}}
$$

In this study, the stage efficiency is considered to be equal to the blade efficiency since the degree of reaction is set equal to 0.5 (i.e. $\eta_{s}=\eta_{b}$ ). For a multi-stage compressor of $n_{s}$ similar stages each providing a temperature rise $\Delta \mathrm{T}_{\mathrm{os}}$ with an isentropic efficiency $\eta_{\mathrm{s}}$, the overall temperature rise is $\mathrm{n}_{\mathrm{s}} \Delta \mathrm{T}_{\mathrm{os}}$, then the overall pressure ratio is given by: 


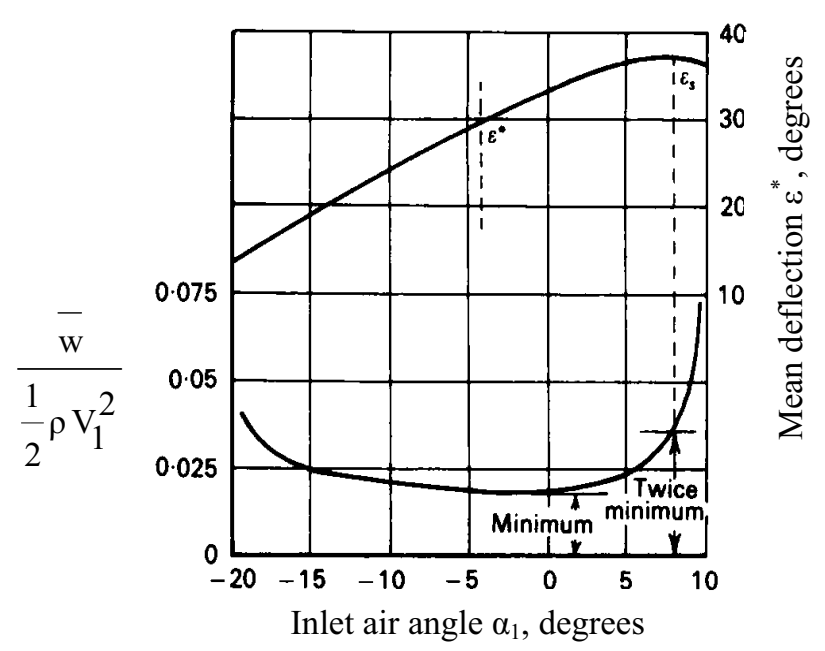

Figure (5): Mean head loss and mean deflection for different inlet air angles

$$
\mathrm{R}_{\mathrm{ov}}=\left[1+\frac{\mathrm{n}_{\mathrm{s}} \Delta \mathrm{T}_{\mathrm{os}}}{\mathrm{T}_{\mathrm{o} 1}}\right]^{\frac{\mathrm{n}}{\mathrm{n}-1}}
$$

where $\frac{\mathrm{n}}{\mathrm{n}-1}=\eta_{\mathrm{s}} \frac{\gamma}{\gamma-1}$ and $\mathrm{n}_{\mathrm{s}}$ : number of stages

2.2 Combustion section: The combustion section consists of combustion chamber, fuel nozzles, flame detection equipment, spark plug and transition pieces. The combustion chamber is arranged concentrically around the axial flow compressor and is bolted to the compressor discharge section bulkhead. Air for combustion is supplied directly from the axial-flow compressor to the combustion chamber. Fuel is fed into the chambers through nozzles that extend into each chamber's liner cap.

The main factors in estimating the combustion chamber performance are the pressure loss, combustion efficiency and air-fuel ratio. The combustion chamber pressure loss is due to skin friction and turbulence, and the rise in temperature due to combustion which causes a stagnation pressure drop often called the fundamental loss, which arise because an increase in temperature implies, a decrease in density and consequently an increase in velocity and momentum of the stream. However, for industrial gas turbine chamber where space and weight are not vital, the ratio of maximum cross-sectional area of the chamber to the mass flow rate of air is normally chosen to yield a value of pressure loss that is little more than $2 \%$ of the combustion chamber entering pressure.

The combustion process efficiency can be found from chemical analysis of the combustion products, but using such method is not an easy task, because it is 
not only difficult to obtain a truly representative sample from high velocity stream, but also, due to the high air-fuel ratio employed in gas turbines which makes the unburned constituents to be measured a very small proportion of the whole sample. Therefore, in the present study, the overall combustion efficiency have been calculated according to the following definition

$$
\eta_{\text {comb }}=\frac{\text { theoretical } f \text { for given } \Delta \mathrm{T}}{\text { actual } \mathrm{f} \text { for given } \Delta \mathrm{T}}
$$

where $f$, represent the fuel-air ratio, and $\Delta \mathrm{T}$ is the temperature difference between one which entered the combustion chamber and the turbine inlet temperature (TIT).

2.3 Axial flow turbine: In the axial flow turbine, the high pressure, high temperature gases from the combustion chamber flow in the annular space to the stationary blades, called stator or nozzles, and are directed tangentially against the rotating blade row, called rotor blades. A simple single stage turbine is shown in figure (6). As in the axial flow compressor, the analysis of axial flow turbine stage is performed along the mean diameter of the annulus. The following assumption have been considered:

1- $\quad$ Assume two-dimensional flow.

2- $\quad$ The mass flow rate through the turbine is assumed to equal to the mass flow delivered by the compressor.

3- The rotational speed, N, of the turbine is the same as that of the compressor.

4- The maximum turbine inlet temperature (TIT) is chosen to be $1030 \mathrm{~K}$.

5- $\quad$ The axial velocity, $\mathrm{C}_{\mathrm{a}}$, is constant.
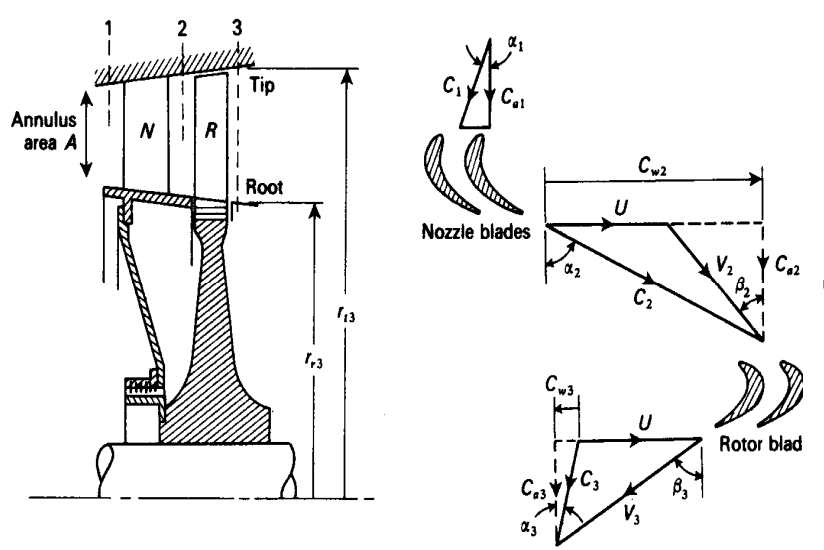

Figure (6): Axial flow turbine

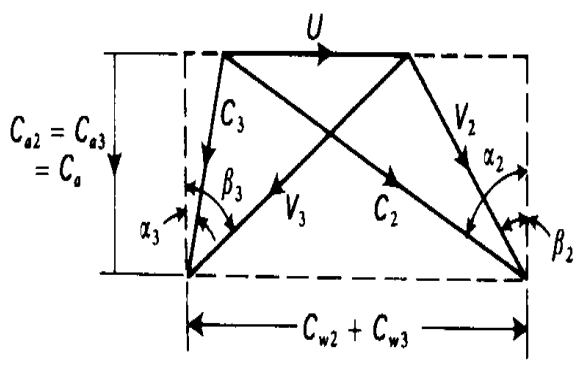

Figure (7): Velocity diagram

Figure (6) show the velocity triangles for a single stage turbine. The combustion gases enter the row of nozzle blades with a static pressure and temperature $\mathrm{P}_{1}, \mathrm{~T}_{1}$ and leave with an increased velocity $\mathrm{C}_{2}$ at an angle $\alpha_{2}$, then entered the rotor blade passage, expand further and leave at $\mathrm{P}_{3}, \mathrm{~T}_{3}$ with relative 
velocity $\mathrm{V}_{3}$ at an angle $\beta_{3}$. These velocity triangles can be superimposed in usual way, keeping in mind that axial velocity is constant, to give a velocity diagram for the stage as shown in figure (7). The velocity diagram gives the relations:

$$
\frac{\mathrm{U}}{\mathrm{C}_{\mathrm{a}}}=\tan \alpha_{2}-\tan \beta_{2}=\tan \beta_{3}-\tan \alpha_{3}
$$

and applying the principle of angular momentum to the rotor, the stage work output per unit mass flow is:

$$
\mathrm{W}_{\mathrm{s}}=\mathrm{U}\left(\mathrm{C}_{\mathrm{w} 2}+\mathrm{C}_{\mathrm{w} 3}\right)=\mathrm{UC}_{\mathrm{a}}\left(\tan \alpha_{2}+\tan \alpha_{3}\right)
$$

Combining equations (26) and (27)

$$
\mathrm{W}_{\mathrm{s}}=\mathrm{UC}_{\mathrm{a}}\left(\tan \beta_{2}+\tan \beta_{3}\right)
$$

and from steady flow energy equation

$$
\mathrm{W}_{\mathrm{s}}=\mathrm{c}_{\mathrm{p}} \Delta \mathrm{T}_{\mathrm{os}}
$$

hence, from equations (27) and (28) the static temperature drop in the stage $\Delta \mathrm{T}_{\text {os }}$ is calculated as:

$$
\Delta \mathrm{T}_{\mathrm{os}}=\frac{\mathrm{UC}_{\mathrm{a}}}{\mathrm{c}_{\mathrm{p}}}\left(\tan \beta_{2}+\tan \beta_{3}\right)
$$

Three dimensionless parameters are significant in the turbine design, they can be presented as follows:

1-The temperature drop coefficient $(\psi)$ : Or sometimes called the blade loading coefficient, which expresses the work capacity of a stage:

$$
\psi=\frac{2 \mathrm{c}_{\mathrm{p}} \Delta \mathrm{T}_{\mathrm{os}}}{\mathrm{U}^{2}}
$$

or in terms of the axial velocity:

$$
\psi=\frac{2 \mathrm{C}_{\mathrm{a}}}{\mathrm{U}}\left(\tan \beta_{2}+\tan \beta_{3}\right)
$$

2-The degree of reaction $\Lambda$ : Which expresses the fraction of the stage expansion that occurs in the rotor and it is usual to define it in terms of static temperature as follows:

$$
\Lambda=\frac{\mathrm{T}_{2}-\mathrm{T}_{3}}{\mathrm{~T}_{1}-\mathrm{T}_{3}}
$$

according to the type of stage which has been considered, a simple expression for $\Lambda$ can be written as follows:

$$
\Lambda=\frac{\mathrm{C}_{\mathrm{a}}}{2 \mathrm{U}}\left(\tan \beta_{3}-\tan \beta_{2}\right)
$$

3-The flow coefficient $(\Phi)$ : It is defined as the ratio of the axial velocity $\left(\mathrm{C}_{\mathrm{a}}\right)$ to the blade speed (U).

$$
\Phi=\frac{\mathrm{C}_{\mathrm{a}}}{\mathrm{U}}
$$

Clearly, it is useful to express the gas angle in term of $\psi, \Lambda$, and $\Phi$, as follows:

$$
\psi=2 \Phi\left(\tan \beta_{2}+\tan \beta_{3}\right)
$$




$$
\Lambda=\frac{\Phi}{2}\left(\tan \beta_{3}-\tan \beta_{2}\right)
$$

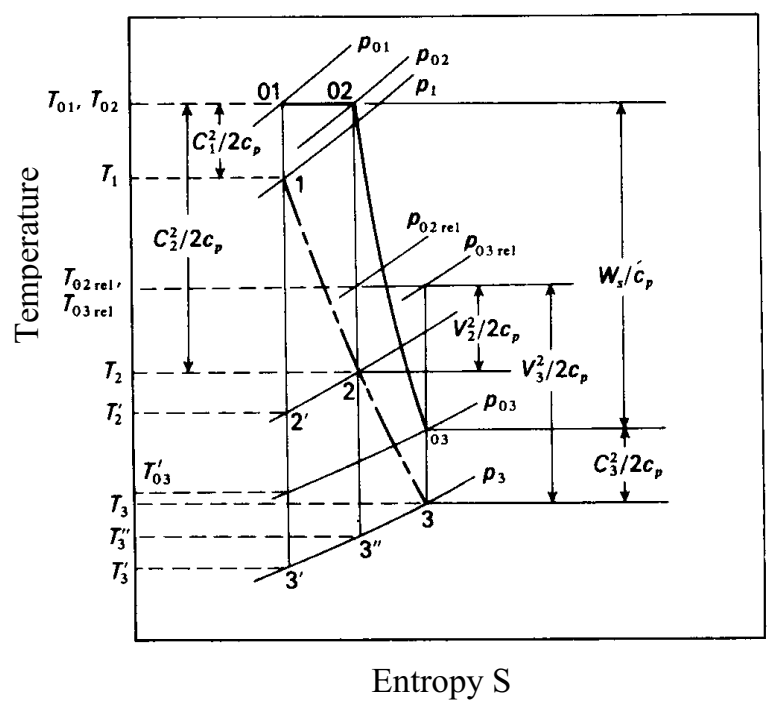

Figure (8): T-S diagram for single stage

Obviously, the values of temperature drop coefficient $(\psi)$, the degree of reaction $\Lambda$ and the flow coefficient $(\Phi)$ should be assumed in order to determine the values of air angle $\left(\alpha_{2}, \alpha_{3}, \beta_{2}\right.$ and $\left.\beta_{3}\right)$. The value of degree of reaction should be close to $50 \%$, while the value of the other two parameter is selected to suit a single stage gas turbine. Also values of mean blade speed (U) and axial velocity $\left(\mathrm{C}_{\mathrm{a}}\right)$ have been assumed.

The next step is to calculate the stage efficiency, therefore, the losses in the blade row should be accounted based upon the temperature and pressure drops. These parameters can be described by sketching the process in the nozzle and rotor blade passage on T-S diagram, shown in figure (8), these losses of course exaggerated in this figure. The loss coefficient for the nozzle blades may be expressed as:

$$
\lambda_{\mathrm{N}}=\frac{\mathrm{T}_{2}-\mathrm{T}_{2}^{\prime}}{\frac{\mathrm{C}_{2}^{2}}{2 \mathrm{c}_{\mathrm{P}}}}
$$

where $\lambda$ express the proportion of the leaving energy which is degraded by friction.

while the rotor blade loss can be expressed as:

$$
\lambda_{\mathrm{R}}=\frac{\mathrm{T}_{3}-\mathrm{T}_{3}^{\prime \prime}}{\frac{\mathrm{V}_{3}^{2}}{2 \mathrm{c}_{\mathrm{p}}}}
$$

and the stage efficiency can be represented as: 


$$
\eta_{\mathrm{s}}=\frac{1}{1+\left[\lambda_{\mathrm{R}}\left(\frac{\mathrm{V}_{3}^{2}}{2 \mathrm{c}_{\mathrm{P}}}\right)+\left(\frac{\mathrm{T}_{3}}{\mathrm{~T}_{2}}\right) \lambda_{\mathrm{N}}\left(\frac{\mathrm{C}_{2}^{2}}{2 \mathrm{c}_{\mathrm{p}}}\right)\right] /\left(\mathrm{T}_{\mathrm{o} 1}-\mathrm{T}_{\mathrm{o} 3}\right)}
$$

or in term of axial velocity

$$
\eta_{\mathrm{s}}=\frac{1}{1+\frac{1}{2} \frac{\mathrm{C}_{\mathrm{a}}}{\mathrm{U}}\left[\frac{\lambda_{\mathrm{R}} \sec ^{2} \beta_{3}+\left(\frac{\mathrm{T}_{3}}{\mathrm{~T}_{2}}\right) \lambda_{\mathrm{N}} \sec ^{2} \alpha_{2}}{\left(\tan \beta_{3}+\tan \alpha_{2}-\frac{\mathrm{U}}{\mathrm{C}_{\mathrm{a}}}\right)}\right]}
$$

The above equation is simply used to calculate the turbine stage efficiency in this study. Thereafter, the annulus area at planes 1, 2 and 3, shown in figure (6) can be calculated using the continuity equation, $m=\rho \mathrm{A} \mathrm{C}_{\mathrm{a}}$. clearly the mass flow rate is equal to that delivered by the compressor and the axial velocity is considered to be constant throughout the turbine stage. While the density at each plane, $\rho_{I}$, can be determined using; $\rho_{i}=\frac{P_{i}}{R^{\circ} T_{i}}$, and values of $T_{I}$ and $P_{I}$ are calculated using isentropic relations. Furthermore, the blade height at planes 1, 2 and 3 can be estimated as:

$$
\mathrm{h}_{\mathrm{i}}=\frac{\mathrm{A}_{\mathrm{i}} \mathrm{N}}{\mathrm{U}}
$$

and the mean radius also can be found as

$$
\mathrm{r}_{\mathrm{m}}=\frac{\mathrm{U}_{\mathrm{m}}}{2 \pi \mathrm{N}}
$$

hence annulus radius ratio may be determined as:

$$
\frac{r_{t}}{r_{r}}=\frac{r_{m}+\left(h_{i} / 2\right)}{r_{m}-\left(h_{i} / 2\right)}
$$

The annulus radius ratio should be in the range of 1.2- 1.4, this means if the rotational speed, $\mathrm{N}$, which has been fixed by the compressor would lead to an illproportioned annulus, for example if high value of $\left(r_{t} / r_{r}\right)$ is obtained, then this could be reduced by increasing the axial velocity, i.e. by using a high value of the flow coefficient $\Phi$.

\section{3- Gas turbine simulation results}

Gas turbine simulation results can be divided in two parts, the first part deals with the gas turbine design results, while the second part provides the performance results, which confirm the validity of the gas turbine system simulation.

3.1- Gas turbine design results: The preliminary design of multistage axial flow compressor is typically based on determining each stage flow properties along the compressor mean line (line along the compressor axis that corresponds to the mean radius). The annulus area at any station is based on flow properties, 
temperature, pressure, Mach number and flow angle at the mean radius and the total mass flow rate of air.

The air inlet and outlet angles $\left(\alpha_{1}, \beta_{1}\right)$ for the axial flow compressor were assessed taking in consideration that the axial velocity is constant, $\mathrm{C}_{\mathrm{a}}$, through all the stages. The stage temperature rise, $\Delta \mathrm{T}_{\mathrm{s}}$, is assumed $17^{\circ} \mathrm{C}$, this value depends on factors such as allowable size, weight of the whole compressor and desired rotational speed $[6,7]$. The selection of rotational speed, $\mathrm{N}$, is not a simple matter. It depends on a balance of the requirements of all components on the common shaft, i.e., the compressor and the turbine. The rotational speed can be found by assuming a value for the mean blade speed, the axial velocity and hub to tip ratio. In this study, the rotational speed has been taken the same as that of Mosul gas turbine power station unit 12, i.e. $5100 \mathrm{rpm}$. Thereafter, the mean radius of the compressor annulus, the height of the blade, pitch to chord ratio and total drag coefficient were found in order to find the stage efficiency of the axial flow compressor and finally the stage pressure ratio. The number of compressor stages depends on the required overall pressure ratio and change in total temperature of each stage. In the present study, the axial flow compressor is found to consist of seventeen similar stages, which is the exact number of stages in the compressor of unit 12 of the Mosul gas turbine power station. A computer program is developed to perform the simulation and the following input data are entered to the computer program:

$$
\begin{aligned}
& \text { Mass flow rate }=81 \mathrm{~kg} / \mathrm{sec} \\
& \text { Rotational speed }=5100 \mathrm{r} . \mathrm{p} . \mathrm{m} \\
& \text { Axial velocity }=150 \mathrm{~m} / \mathrm{sec} \\
& \text { Degree of reaction }=0.5 \\
& \text { Stage temperature rise }=17{ }^{\circ} \mathrm{C} \\
& \text { Mean blade speed }=180 \mathrm{~m} / \mathrm{sec} \\
& \text { Aspect ratio }=3.0
\end{aligned}
$$

A summary of the seventeen stages results of the compressor is given in table (1). However, since repeating stage design is considered in this study, i.e. $\alpha_{1}=\beta_{2}$ and $\alpha_{2}=\beta_{1}$. Th output values of axial velocity, mean blade speed are found to be different from the input values, because the computer program perform an iterative procedure to arrange these values in such a way with the rotational speed to have a reasonable Mach number at the entrance of the compressor.

In the combustion chamber, the pressure losses are considered as $2 \%$ of the combustion chamber inlet pressure. The fuel-air ratio and specific heat of the combustion products were calculated by assuming that the gas turbine fuel is $100 \% \mathrm{CH}_{4}$ natural gas. According to the ISO rating conditions, the value of specific heat was found to be $1.133 \mathrm{~kJ} / \mathrm{kg} . \mathrm{K}$, while the value of fuel-air ratio is 0.01362 . With regard to the axial flow turbine, the following data were adopted:

Turbine inlet temperature $=1030 \mathrm{~K}$

Temperature drop, $\Delta \mathrm{T}_{\mathrm{os}}=300 \mathrm{~K}$

Inlet angle $\alpha_{1}=10$ degree

Mean blade speed $U=300 \mathrm{~m} / \mathrm{sec}$

Flow coefficient $\Phi=0.8$

Nozzle loss coefficient $\lambda_{\mathrm{N}}=0.05$ 
Table (1): Summary of the seventeen stages simulation results.

\begin{tabular}{||c|c|c|c|c|c|c|c|c||}
\hline $\begin{array}{c}\text { Stage } \\
\text { Number }\end{array}$ & $\begin{array}{c}\text { Pressure } \\
\text { ratio }\end{array}$ & $\begin{array}{c}\text { Mach } \\
\text { number }\end{array}$ & $\begin{array}{c}\text { Static } \\
\text { temp.( K) }\end{array}$ & $\begin{array}{c}\text { Static } \\
\text { pressure } \\
\text { (kpa) }\end{array}$ & $\mathbf{r}_{\mathbf{t}}(\mathbf{m})$ & $\mathbf{r}_{\mathbf{r}}(\mathbf{m})$ & $\begin{array}{c}\text { Number } \\
\text { of blades }\end{array}$ & $\begin{array}{c}\text { Annulus } \\
\text { area }\left(\mathbf{m}^{\mathbf{2}}\right)\end{array}$ \\
\hline $\mathbf{1}$ & 1.198 & 0.651 & 288 & 101.3 & 0.505 & 0.356 & 28 & 0.405 \\
\hline $\mathbf{2}$ & 1.186 & 0.633 & 305 & 122.5 & 0.497 & 0.364 & 32 & 0.360 \\
\hline $\mathbf{3}$ & 1.176 & 0.616 & 322 & 146.4 & 0.49 & 0.371 & 36 & 0.321 \\
\hline $\mathbf{4}$ & 1.167 & 0.600 & 339 & 173.4 & 0.484 & 0.377 & 40 & 0.289 \\
\hline $\mathbf{5}$ & 1.158 & 0.586 & 356 & 203.6 & 0.479 & 0.382 & 44 & 0.261 \\
\hline $\mathbf{6}$ & 1.151 & 0.572 & 373 & 237.2 & 0.474 & 0.387 & 49 & 0.237 \\
\hline $\mathbf{7}$ & 1.144 & 0.560 & 390 & 274.3 & 0.471 & 0.391 & 54 & 0.216 \\
\hline $\mathbf{8}$ & 1.137 & 0.548 & 407 & 315.3 & 0.467 & 0.394 & 59 & 0.197 \\
\hline $\mathbf{9}$ & 1.132 & 0.537 & 424 & 360.1 & 0.464 & 0.397 & 64 & 0.182 \\
\hline $\mathbf{1 0}$ & 1.126 & 0.526 & 441 & 409.2 & 0.462 & 0.4 & 69 & 0.167 \\
\hline $\mathbf{1 1}$ & 1.122 & 0.517 & 458 & 462.6 & 0.459 & 0.402 & 75 & 0.154 \\
\hline $\mathbf{1 2}$ & 1.117 & 0.507 & 475 & 520.6 & 0.457 & 0.404 & 81 & 0.143 \\
\hline $\mathbf{1 3}$ & 1.113 & 0.498 & 492 & 583.3 & 0.455 & 0.406 & 87 & 0.133 \\
\hline $\mathbf{1 4}$ & 1.101 & 0.49 & 509 & 651.0 & 0.454 & 0.408 & 94 & 0.124 \\
\hline $\mathbf{1 5}$ & 1.105 & 0.482 & 526 & 723.8 & 0.452 & 0.409 & 101 & 0.116 \\
\hline $\mathbf{1 6}$ & 1.102 & 0.474 & 543 & 802.0 & 0.451 & 0.411 & 108 & 0.108 \\
\hline $\mathbf{1 7}$ & 1.099 & 0.467 & 560 & 885.7 & 0.449 & 0.412 & 115 & 0.101 \\
\hline
\end{tabular}

In addition to the above data, the air mass flow rate, rotational speed and turbine inlet pressure are fixed by the axial flow compressor data. The axial velocity is assumed to be constant, its value was $180 \mathrm{~m} / \mathrm{sec}$. First of all, from the given data, the computer program calculates the temperature drop coefficient $\psi$. Thereafter, the degree of reaction can be calculated and checked at the mean radius. Its value should be close to 0.5 , otherwise the flow coefficient $\Phi$ and inlet angle $\alpha_{1}$ should be adjusted. This iterative procedure is continued until the value of the degree of reaction approaches the actual value. The value of the degree of reaction in this study was found to be 0.534 , at value of $\Phi=0.6$ and $\alpha_{1}=10$ degree.

At this point the gas angles can be estimated and the density at planes 1,2 and 3 is calculated. The blade height $h$ and the tip/root radius can be estimated as shown in table (2). The pressure and temperature at each plane was calculated using the dynamic temperature $\left(\mathrm{C}^{2} / 2 \mathrm{c}_{\mathrm{p}}\right)$ and isentropic relations, their values are given in table (2). The annulus area at planes 1,2 and 3 shown in figure (7), were calculated since the densities at each plane are available at the mean radius. Finally, the rotor blade losses $\lambda_{R}$ is assessed, its value is found to be 0.19 , in order to calculate the turbine stage efficiency, which was found to be $90 \%$. A complete summary of the above discussed results is shown in table (2). 
Table (2) summary of results that obtained for single stage axial flow turbine design calculation.

\begin{tabular}{|c|c|c|c|c|c|c|c|c|}
\hline \multicolumn{3}{|c|}{ Gas angle (degree) } & $\alpha_{1}$ & \multicolumn{2}{|c|}{$\mathrm{A}_{2}$} & & $\beta_{2}$ & $\beta_{3}$ \\
\hline \multicolumn{3}{|l|}{ Root } & $10^{\circ}$ & \multicolumn{2}{|c|}{$53^{\circ}$} & $4.5^{\circ}$ & $49^{\circ}$ & $50.4^{\circ}$ \\
\hline \multicolumn{3}{|l|}{ Mean } & $10^{\circ}$ & \multicolumn{2}{|c|}{$50^{\circ}$} & $1^{\circ}$ & $48.3^{\circ}$ & $50.2^{\circ}$ \\
\hline \multicolumn{3}{|l|}{ Tip } & $10^{\circ}$ & \multicolumn{2}{|c|}{$51^{\circ}$} & $0^{\circ}$ & \multirow{2}{*}{$\begin{array}{c}\rho \\
\left(\mathrm{kg} / \mathrm{m}^{3}\right)\end{array}$} & $50^{\circ}$ \\
\hline Plane & $\mathrm{T}(\mathrm{K})$ & $\mathrm{P}$ (bar) & & $\mathrm{A}\left(\mathrm{m}^{2}\right)$ & $\mathrm{r}_{\mathrm{t}} / \mathrm{r}_{\mathrm{r}}$ & $\mathrm{R}_{\mathrm{m}}(\mathrm{m})$ & & $\mathrm{h}(\mathrm{m})$ \\
\hline 1 & 928 & 5.722 & & 0.2377 & 1.108 & 0.568 & 2.14 & 0.0586 \\
\hline 2 & 783 & 2.71 & & 0.338 & 1.151 & 0.568 & 1.42 & 0.0881 \\
\hline 3 & 638 & 1.85 & & 0.387 & 1.169 & 0.568 & 1.205 & 0.104 \\
\hline \multicolumn{3}{|c|}{ Blade row } & \multicolumn{3}{|c|}{ Nozzle } & \multicolumn{3}{|c|}{ Rotor } \\
\hline \multicolumn{3}{|c|}{$\mathrm{s} / \mathrm{c}$} & \multicolumn{3}{|c|}{0.78} & \multicolumn{3}{|c|}{0.72} \\
\hline \multicolumn{3}{|c|}{$\mathrm{h} / \mathrm{c}$} & \multicolumn{3}{|c|}{3.0} & \multicolumn{3}{|c|}{3.0} \\
\hline \multicolumn{3}{|c|}{$\mathrm{n}_{\mathrm{b}}$} & \multicolumn{3}{|c|}{192} & \multicolumn{3}{|c|}{154} \\
\hline
\end{tabular}

3.2 Gas turbine performance results: In order to examine the validity of the developed simulation procedure, the behavior of the system, in terms of its states and performance parameters under various ambient temperatures were observed for two main cases, those are: I- variable power output at constant turbine inlet temperature (TIT) condition and, II-constant power output under variable turbine inlet temperature (TIT) condition. The simulated results of case I is compared with field data taken from unit 12 of the Mosul gas turbine power station. Of course, case II is a hypothetical one governed by the technological limitation on the turbine inlet temperature (TIT), thus no field data can obtained for making a comparison.

I- Variable power output case: In this case the turbine inlet temperature was kept constant at $1030 \mathrm{~K}$, and the variation of the operating parameters and states were observed with the ambient temperature variation. The performance results of this case are shown in figures (9) to (15). Figure (9) shows the relationship between the mass flow rate of air discharged by the compressor and the ambient temperature. It was found that there is nearly $10 \%$ reduction in the mass of air from the design value as the temperature reaches $45{ }^{\circ} \mathrm{C}$. This is due to the decrease in density of the ambient air with the increase of its temperature which affect the mass flow rate of air delivered by the compressor and eventually the compressor pressure ratio. It was found that the compressor pressure ratio decreases by nearly $14 \%$, as shown in figure (10).

Examining figure (10) indicates that the field data is relatively lower than that of simulated results nearly by 1 to $2 \%$. This simply can be related to compressor fouling because the most obvious sign of compressor fouling is a loss in compressor delivery pressure $[8,9,10]$. Compressor fouling can be described as follows: the gas turbine draws in a large quantity of air directly from atmosphere that may bring a variety of material, mainly dust and other airborne particles, which can be deposited on the compressor blades, resulting in both a reduction in flow area and change in blade shapes. This leads to decrease in compressor flow and isentropic efficiency. Moreover, the isentropic efficiency decrease turns to affect the compressor delivery pressure, i.e. low compressor pressure ratio that ultimately affects all other operating parameters including compressor work, specific fuel consumption, work ratio, power output and finally the thermal efficiency as will be shown hereafter in the coming results. Saravanamutto H. I. 
H. et.al $[8,9,10]$ reported that the compressor fouling results in decrease of compressor pressure ratio which affects other operating parameters such as specific fuel consumption, work ratio and power output.

Figure (11) shows the behavior of the simulated and field data compressor work for various ambient temperatures. As expected, the reduction in mass flow rate of air resulted in a significant decrease in the compressor work which reached $9.15 \%$ as the ambient temperature is raised to $45{ }^{\circ} \mathrm{C}$. The field data is relatively higher than that of simulated results by nearly 1 to $2 \%$ due to the compressor fouling. In figure (12) the specific fuel consumption is plotted against the ambient temperature for both field data and simulated results. It was found that the specific fuel consumption increases by approximately $15 \%$. The relatively high increase is due to the reduction in the pressure ratio and compressor work, which made it necessary to increase the mass flow rate of fuel to keep the turbine inlet temperature constant at $1030 \mathrm{~K}$. Again the field data is relatively higher than that of the simulated results by nearly 1 to $2 \%$ due to compressor fouling. Similar results were showed by Saravanamutto H. I. H. et.al [10]. Figure (13) indicates that the work ratio (net work/ turbine work) decreases as the ambient temperature increase for both field data and simulated results. This is due to the fact that the reduction in the turbine work is higher than the reduction in the compressor work, $(14.8 \%$ and $9.15 \%)$ respectively. Again, compressor fouling is behind the discrepancy between the field data and simulated data. As expected, the power output was found to decrease as ambient temperature increase, as shown in figure (14). This is due to the reduction in the mass flow rate of air with ambient temperature rise which affect the pressure ratio and the turbine work and ultimately the power output. The reduction in power output was found to be $21 \%$ as the ambient temperature reaches $45 \%$. Examining figure (15) indicates that field power output is relatively lower than that of the simulated one. Similar pattern was observed by Saravanamutto H. I. H. et.al $[9,10]$ as a result of compressor fouling. Finally, figure (15) shows the relationship between the thermal efficiency and ambient temperature. Of interest is the relatively low decrease in the thermal efficiency with ambient temperature compared to the power output due to the decrease in the power output and the slight increase in specific fuel consumption. In this case the thermal efficiency was found to decrease by nearly $13 \%$ as the ambient temperature approaches $45{ }^{\circ} \mathrm{C}$. Again the field data is lower than the simulated results due to compressor fouling $[9,10]$.

II- Constant power output case: In this case the turbine inlet temperature (TIT) is allowed to increase as the ambient temperature increase to obtain a constant power production equal to the gas turbine generator design value. The variation of the operating parameters of the compressor including the mass flow rate of air, pressure ratio and the compressor work was found to be identical to that of case I. Therefore, figures (9), (10) and figure (11) shows the variation of the above mentioned operating parameters of the compressor with ambient temperature for both cases, i.e. the variable power output case as well as the constant power output case. Figure (16) shows the relationship between the specific fuel consumption and ambient temperature. It was found that the specific fuel consumption increases by nearly $10.7 \%$ as the ambient temperature reaches 
$45{ }^{\circ} \mathrm{C}$. In fact this is due to the slight increase in fuel-air ratio to obtain the required turbine inlet temperature which eventually resulted in producing a constant power despite of the ambient temperature rise. Figure (17) shows the variation of the work ratio with ambient temperature. It was found that the work ratio increases by approximately $4.8 \%$. This is due to the increase in the turbine inlet temperature that leads to increase in the turbine work and ultimately in the increase of the work ratio. The turbine inlet temperature was found to increase by nearly $12.2 \%$, shown in figure (18), as the ambient temperature reaches $45^{\circ} \mathrm{C}$. In figure (19) the thermal efficiency is plotted against the ambient temperature. It was found that the thermal efficiency decreases by nearly $8.6 \%$. This is due to the increase of the specific fuel consumption to obtain a constant power production equal to the design value of the gas turbine generator. The above analysis was carried out under the assumption that the metallurgical constraints on the gas temperature can be released through advancements in materials technology. Even so, gas turbine manufacturers does not recommend working at high temperatures due to the reduced lifetime of the entire plant equipments such as bearings, chimney, pumps and others. Therefore, it seems that for the time being, the inlet air cooling procedure is the optimum solution to the power reduction problem. The above obtained results from the variable TIT analysis are still good guides for future applications.

\section{References}

1- Johnson R. S., The theory and Operation of Evaporative Cooler for Industrial Gas Turbine, Journal of Engineering for Gas Turbine and Power, Vol. 111, pp.327-334, April 1989.

2- Frank J. Brook, GE Gas turbine performance characteristics, GE Power system, Oct. 2001.

3- Jan Szargut, Influence of the Ambient Temperature on the Operational Indices of the Gas Turbine Set, International Journal of Energy Research, Vol. 24, pp. 821-830, 1999.

4- $\quad$ Yunus A. Cengel, Michael A. Boles 1998, Thermodynamic an engineering approach.

5- Filsinger D., Gutmann C., Design of Thermally High-Loaded Ceramic Components for Gas Turbine, Journal of European Ceramic Society, Vol.17, pp. 1655-1663, 1997.

6- Cohen H., Rogers G.F.C, and Saravanamuttoo, H.I.H 1987, Gas turbine theory, $3^{\text {rd }}$ editions. Longman.

7- Jack D. Mattingly 1996, Element of gas turbine propulsion, McGraw-Hill book company.

8- Saravanamuttoo H. I. H., Lakshminarasimha, A. N., A preliminary Assessment of Compressor Fouling, ASME Paper No. 85-Gt-38, 1985.

9- $\quad$ Saravanamuttoo H. I. H, Aker G.F., Predicting Gas Turbine Performance Degradation Due to compressor Fouling Using Computer Simulation Techniques, Journal of Engineering for Gas Turbine and Power, Vol. 111, pp. 343-349, 1989. 
10- Lakshminarasimha A. N., Saravanamuttoo H. I. H, Prediction of Fouled Compressor Using Stacking Techniques, ASME Symposium on Turbomachinery Performance Deterioration, Vol.37, 1986.

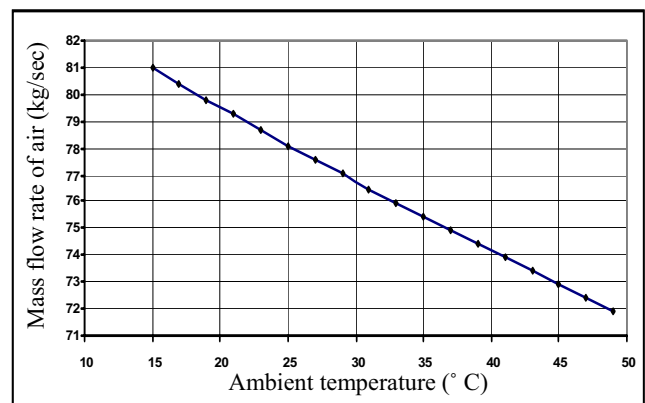

Figure (9): Effect of ambient temperature on the mass flow rate of air

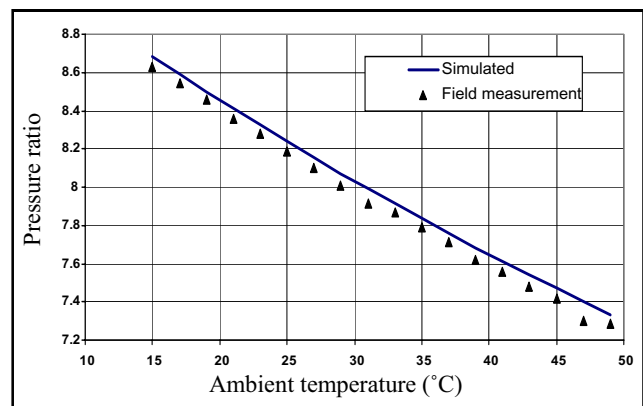

Figure (10): Effect of ambient temperature on the pressure ratio

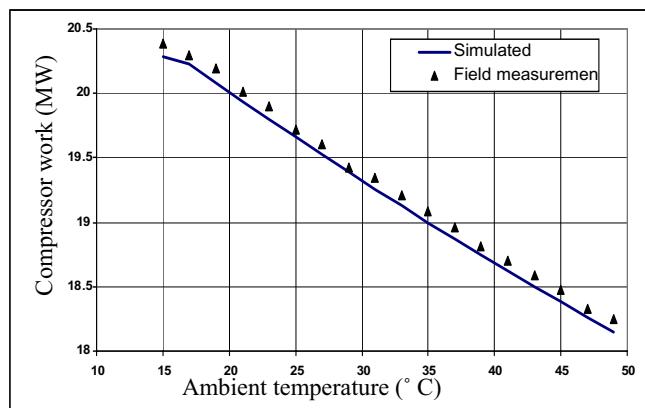

Figure (11): Variation of the compressor work with ambient temperature

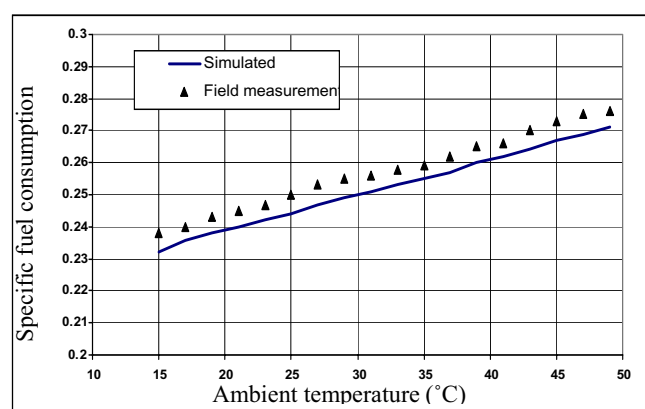

Figure (12): Effect of ambient temperature on the specific fuel consumption, at constant TIT

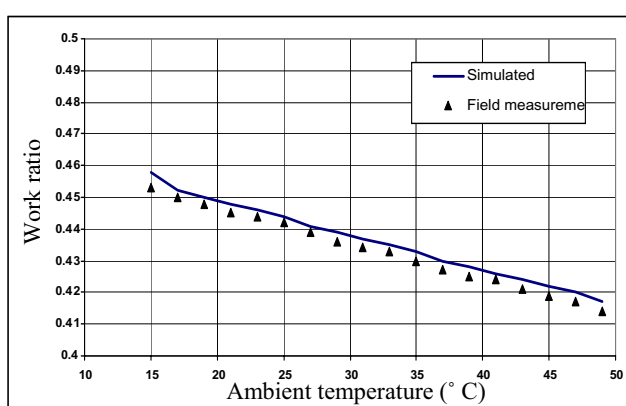

Figure (13): Effect of ambient temperature on the work ratio, at constant TIT

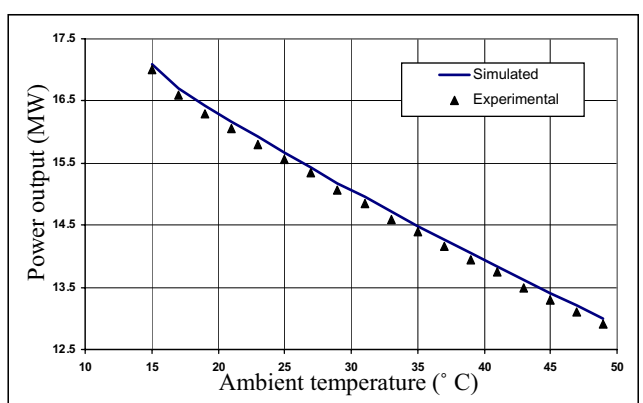

Figure (14). Effect of ambient temperature on the power output, at constant TIT

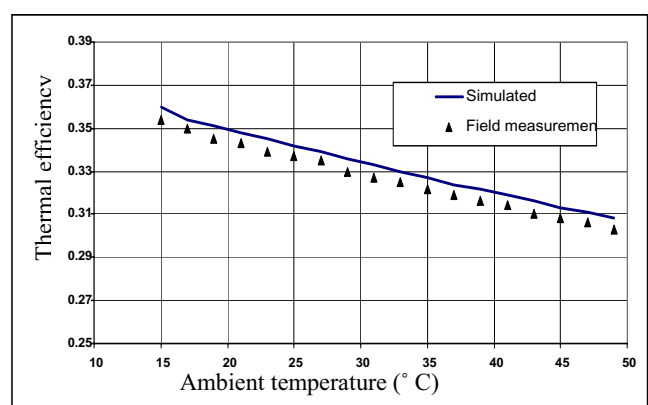

Figure (15): Variation of the thermal efficiency with ambient temperature, at constant TIT 


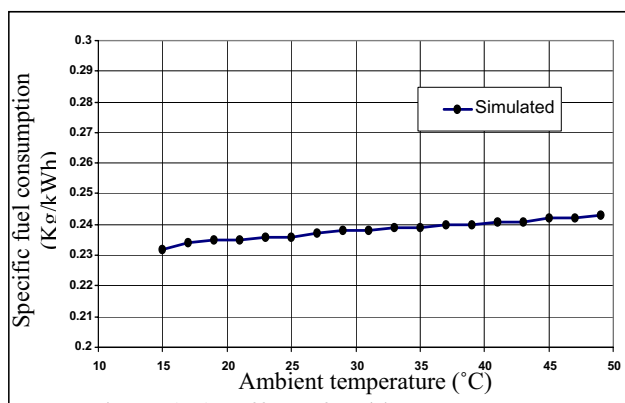

Figure (16): Effect of ambient temperature on the specific fuel consumption, at variahle TIT

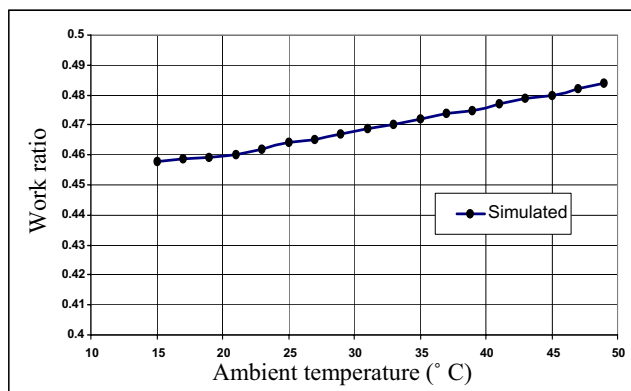

Figure (17): Effect of ambient temperature on the work ratio, at variable TIT

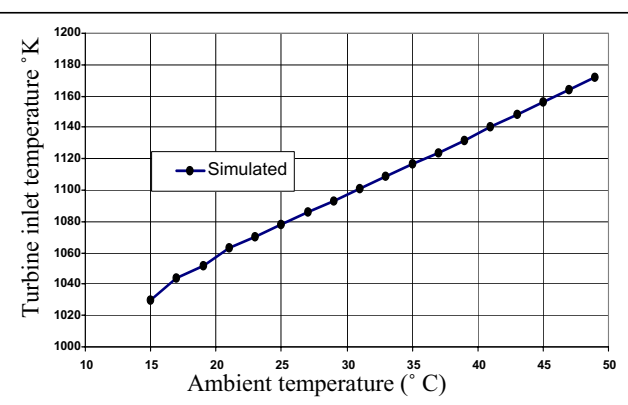

Figure (18). Effect of ambient temperature on the TIT at ennstant nower nutnut

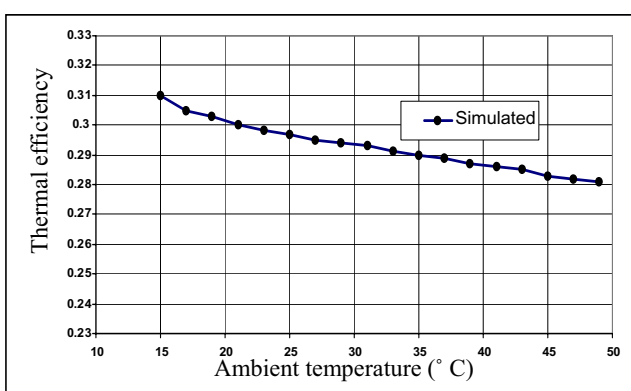

Figure (19): Effect of ambient temperature on the thermal efficiency, at variable TIT 